\title{
A possible role for the dorsolateral protocerebral neurosecretory neurons in the trophic adaptations of Lymantria dispar (Lepidoptera: Lymantriidae)
}

\author{
VESNa PERIĆ-MATARUGA ${ }^{1}$, JELICA LAZAREVIĆ and VERA NENADOVIĆ \\ Institute for Biological Research "Siniša Stanković", 29 Novembra 142, 11060 Belgrade, Yugoslavia; e-mail: \\ vesper@ibbi.ibiss.bg.ac.yu
}

Key words. Nutritive stress, protocerebral dorsolateral neurosecretory neurons, corpora allata, Lymantria dispar, oak, locust-tree

\begin{abstract}
The activity and number of protocerebral neurosecretory neurons of the dorsolateral group (L1, L2 and L2'), as well as the size of the corpora allata were investigated in 5th instar larvae of the gypsy moth (Lymantria dispar) from two populations (oak and locust-tree forests) fed one of two host-plants (oak is a suitable and locust-tree an unsuitable host-plant).

The monitoring of activity related cytological parameters and the number of protocerebral dorsolateral neurosecretory neurons revealed that differently adapted populations respond to nutritive stress differently. The activity of the L 1 neurosecretory neurons in the protocerebra of the caterpillars is low in those from the locust-tree forest regardless of host-plant quality. The L2 neurosecretory neurons in the oak population become active when they were fed the unsuitable host-plant whereas their activity was high in locusttree caterpillars regardless of the host-plant. A decrease in the number of neurosecretory neurons in a response to a novel food was noticed in both populations. The activity of the L2' neurosecretory neurons was similar in all caterpillars, but their number was increased in those from the locust-tree forest. The corpora allata of the locust-tree caterpillars were large whereas those of the oak forest caterpillars only increased in size when they were fed locust-tree leaves.

It is obvious that nutritive stress results in neurosecretory reorganization and changes in the titre of hormones that modulate the morphogenetic programme.
\end{abstract}

\section{INTRODUCTION}

The gypsy moth, Lymantria dispar L. (Lepidoptera: Lymantriidae), defoliates forest and fruit trees in temperate areas and is a serious pest throughout Eurasia (Elkinton \& Liebhold, 1990). It is well studied ecologically (Barbosa et al., 1978; Rossiter, 1991; Stockoff, 1991) but its neuroendocrinology is poorly understood (Mitsuhashi, 1963; Loeb \& Hayes, 1980). This work is a continuation of our previous investigations into the role of the neurosecretory neurons of the gypsy moth in their adaptation to unsuitable host-plants (Perić-Mataruga, 1997; Perić-Mataruga et al., 1998; Perić-Mataruga et al., 1999).

The neuroendocrine system quickly reacts to environmental changes (Ivanović \& Janković-Hladni, 1991; Downer \& Laufer, 1984). Its activity determines the content and interrelation of hormones, and the metabolic activity of insects, which affects metamorphosis (Borkovec \& Gelman, 1986). In order to understand how polyphagous phytophagous species change their host range, it is necessary to study adaptations at the level of the neuroendocrine system.

The knowledge on the dorsolateral neurosecretory neurons capable of releasing paraldehyde fuchsin positive peptidergic neurosecretory material is incomplete in the Lymantria dispar (Loeb \& Hayes, 1980).

In addition to other neurohormones, allatostatins are synthesized in the dorsolateral neurosecretory neurons (NSN) of the insect protocerebrum (Veelaert et al., 1995), along with the large form of the prothoracicotropic neurohormone (PTTH) (Agui et al., 1979; Dai et al., 1994).
They are regulators of the metabolic and morphogenetic processes in insects (Raabe, 1982; Gilbert et al., 1996). The allatostatins inhibit corpora allata (CA) activity, i. e. they affect the biosynthesis of juvenile hormones $(\mathrm{JH})$ (Okuda \& Tanaka, 1997). The absence of allatostatins and/or presence of allatotropic neurohormones from the medial part of the protocerebrum stimulates the CA (Bogus \& Scheller, 1994; Meng-Ping et al., 2001). The investigations on various species suggest that there is a correlation between the CA secretory activity and volume (Pszczolkowski \& Chiang, 2000).

The large form of the PTTH has a tropic effect on the prothoracic gland by inducing the synthesis of ecdysone (Kelly et al., 1986; Fescemyer et al., 1995). Exogenous and endogenous factors that change the activity of neurosecretory neurons, and their number, also change the neurohormonal balance and thus the dynamics of insect development (Ivanović et al., 1989; Ivanović et al., 1991; Ivanović \& Janković-Hladni, 1991). Changes in the activity of the neuroendocrine system of phytophages, that have important role in overcoming the negative effects of defense mechanisms of plants, could be important in the broadening of their host range. According to their effects on gypsy moth performance and preference, the locust-tree is ranked as an unsuitable host, and oak as suitable (Liebhold et al., 1995).

L. dispar is very scarce in the locust-tree forests. The locality "Bagremara" (from which the egg masses used in our experiments originate) was planted with locust-trees after the gradual clearing of the oak forest. Therefore, it is presumed that this locust-tree gypsy moth population 

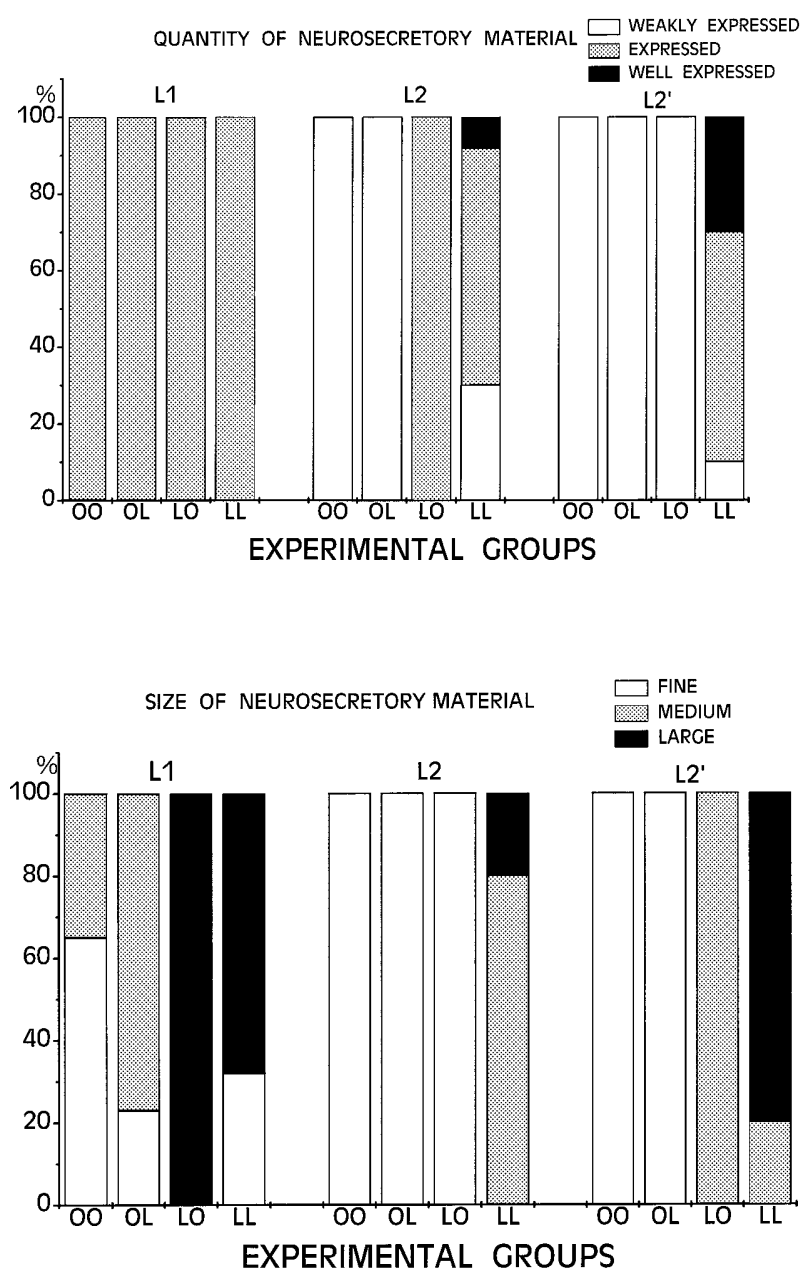

Fig.1. The quantity and size of PAF+ neurosecretory material in the neurosecretory neurons (L1, L2, L2') of 5th instar larvae of Lymantria dispar L. from two populations, fed on different host plants. The abbreviations are as in Table 1.

gradually adapted to an unfavourable diet (Sidor \& Jodal, 1983).

The aim of our study was to determine the population differences in plasticity of response to an unsuitable diet in terms of the level of activity and number of protocerebral neurosecretory neurons in the dorsolateral group (L1, L2 and L2'), and the size of the corpora allata in 5th instar larvae of the gypsy moth.

\section{MATERIAL AND METHODS}

\section{Experimental animals}

The caterpillars of Lymantria dispar L. originated from an oak forest - Quercus rubra (locality Sremački Rt) and a locusttree forest - Robinia pseudoacacia (locality Bagremara). The caterpillars were reared in $200 \mathrm{~cm}^{3}$ plastic containers at a temperature of $23^{\circ} \mathrm{C}$ and a $16 \mathrm{~L}: 8 \mathrm{D}$ light regime, and were fed fresh food daily. The caterpillars were killed three days after moulting to the 5th instar. After hatching, the larvae were distributed to the following experimental groups (three individuals per group):

i. (OO) oak forest origin, fed on oak leaves from hatching;

ii. (OL) oak forest origin, fed on locust-tree leaves from hatching; iii. (LO) locust-tree forest origin, fed on oak tree leaves from hatching;

iv. (LL) locust-tree forest origin, fed on locust-tree leaves from hatching.

\section{Histological techniques}

The effects of the host-plant on the activity of the neurosecretory neurones were detected in the caterpillars on the third day after moulting to the 5 th larval instar. After the caterpillars were killed, their head capsules were fixed in Bouin's fixative. The brain complexes were dissected out and after rinsing and dehydration embedded in paraffin wax (MERCK $59^{\circ} \mathrm{C}$ ). Serial 3.5 $\mathrm{mm}$ thick cross-sections of the brain were stained with Ewen's paraldehyde fuchsin (Ewen, 1962). Neurosecretory granules in neurons stained dark purple-paraldehyde fuchsin positive $(\mathrm{PAF}+)$.

\section{The dorsolateral neurosecretory neurons}

Based on their morphological characteristics, we divided the dorsolateral neurosecretory neurons (for ease of monitoring the results) into groups: L1, L2 and L2' (Fig.2). The size of the L1 neurosecretory neurons (the mean value of the smallest and largest diameters) ranged approximatively from $9 \mu \mathrm{m}$ to $13 \mu \mathrm{m}$. Depending on the physiological state of the neurones both fine grained and large grained $\mathrm{PAF}+$ neurosecretory material, which can form agglomerations, were observed in their cytoplasm (Fig. 4).

The L2 neurosecretory neurons ranged in size from $14.5 \mu \mathrm{m}$ to $18 \mu \mathrm{m}$. The smallest PAF+ neurosecretiory granules were found in the cytoplasm of the L2 neurons (Fig. 4).

The size of the L2' neurosecretory neurons ranged from 18.5 to $21.5 \mu \mathrm{m}$. Both large and fine grained PAF+ neurosecretion was present in the cytoplasm, depending on physiological activity (Fig. 4).

\section{The activity of the neurosecretory neurons}

The activity of the protocerebral neurosecretory neurons ( $\mathrm{L} 1$, L2 and L2') was determined by monitoring the following cytological parameters:

i. The size of the neurosecretory neurons, expressed as the mean value of the smallest and largest diameter (in $\mathrm{mm}$ );

ii. The size of the nucleus, expressed as the mean value of the smallest and largest diameter (in $\mathrm{mm}$ );

iii. The number of nucleoli in the nuclei of more than $80 \%$ of the neurosecretory neurons;

iv. The number of the paraldehyde stained $(\mathrm{PAF}+)$ neurosecretory granules in the perikaryon and the percentage of them that were well expressed, expressed and poorly expressed;

v. Similarly, the size of the PAF+ neurosecretory granules were categorised as fine, medium or large grained (and expressed as a percentage).

Changes in these parameters will be referred to as changes in activity.

The induction of neurosecretory neuron activity, in the sense of the synthesis of the neurosecretory material, is related to an increase in the diameter of nuclei and the presence of large and clearly visible nucleoli (Thomsen, 1965; Hiruma \& Agui, 1977; Raab, 1982). The research on neurosecretory neurons shows that the presence of large agglomerations of neurosecretion is related to its retention in the cytoplasm (Thomsen, 1965; Scharer \& Weitzman, 1970). The presence of small agglomerations of neurosecretion points to a faster release from the neurons (Highnam, 1967; Illyinskaya, 1968; Kind, 1968). 
TABLE 1. The means and standard errors for the small and large diameters of the L1, L2 and L2' dorsolateral protocerebral neurosecretory neurons (DN) and their nuclei (Dn), the number of nucleoli in the nuclei (Nnn) and the number of dorsolateral neurosecretory neurons $(\mathrm{N})$ in 5th instar larvae of Lymantria dispar. OO - caterpillars from the oak forest fed on oak leaves ; OL caterpillars from the oak forest fed on locust-tree leaves; LO - caterpillars from the locust-tree forest fed on oak leaves; LL - caterpillars from the locust-tree forest fed on locust-tree leaves.

\begin{tabular}{llcccc}
\hline & & \multicolumn{2}{c}{ Experimental groups } \\
\cline { 3 - 6 } & & OO & OL & LO & LL \\
\hline L1 & DN $(\mu \mathrm{m})$ & $12.18 \pm 0.73$ & $11.39 \pm 0.17$ & $9.10 \pm 0.15$ & $11.39 \pm 0.19$ \\
& Dn $(\mu \mathrm{m})$ & $5.96 \pm 0.18$ & $5.61 \pm 0.19$ & $5.80 \pm 0.09$ & $5.35 \pm 0.17$ \\
& Nnn & 1 & 1 & 1 & 1 \\
& N & $4.67 \pm 0.41$ & $3.33 \pm 0.41$ & $3.33 \pm 0.41$ & $4.33 \pm 0.41$ \\
L2 & DN $(\mu \mathrm{m})$ & $18.09 \pm 0.16$ & $14.68 \pm 0.80$ & $15.70 \pm 0.39$ & $16.08 \pm 0.50$ \\
& Dn $(\mu \mathrm{m})$ & $6.91 \pm 0.19$ & $6.64 \pm 0.29$ & $7.40 \pm 0.15$ & $6.86 \pm 0.39$ \\
& Nnn & 1 & 2 & 2 & 2 \\
& N & $5.67 \pm 0.41$ & $3.67 \pm 0.82$ & $3.33 \pm 0.41$ & $6.00 \pm 0.71$ \\
L2 & DN $(\mu \mathrm{m})$ & $18.50 \pm 0.22$ & $17.50 \pm 0.35$ & $20.21 \pm 0.35$ & $21.03 \pm 0.28$ \\
& Dn $(\mu \mathrm{m})$ & $7.28 \pm 0.45$ & $7.57 \pm 0.27$ & $7.42 \pm 0.17$ & $7.11 \pm 0.40$ \\
Nnn & 2 & 1 & 2 & 2 \\
N & $3.33 \pm 0.41$ & $2.33 \pm 0.41$ & $3.67 \pm 0.41$ & $6.33 \pm 0.82$ \\
\hline
\end{tabular}

\section{The size of the corpora allata}

The size of the corpora allata is expressed as the mean value of the smallest and largest diameters (in $\mu \mathrm{m}$ ). The data were obtained by measuring 15 corpora allata.

\section{The number of the neurosecretory neurons}

Each neurosecretory neuron was observed in all of the sections in which it appeared, and the number of neurons in each class (L1, L2, L2') was noted for each animal.

\section{Data analysis}

All the histological parameters were analysed with a Leica QWIN program. Forty-seven L1, fifty-six L2 and forty-seven L2' neurosecretory neurons were monitored.

The significance of population, host-plant and interaction effects were estimated using two-way ANOVA (Sokal \& Rohlf 1981).

\section{RESULTS}

\section{Activity of the L1 neurosecretory neurons}

The cytological parameters indicate that there were differences in the activity of the protocerebral L1 neurosecretory neurons in the gypsy moth caterpillars from locust-tree and oak forest populations.

The average diameter of the L1 neurosecretory neurons in caterpillars from the locust-tree forest, which were fed with oak leaves was significantly less than that of the other experimental groups (Table 1). The L1 cells of the caterpillars from the locust-tree forest mostly contained large-grained $\mathrm{PAF}+$ neurosecretion, which tended to form agglomerations regardless of food quality (Fig.1, Fig. 4). This indicates that it is being retained or slowly released from the neurons.

The L1 neurons in caterpillars from the oak forest had mainly fine-grained PAF+ neurosecretory material when fed on oak leaves, and medium-grained if fed on locusttree leaves (Fig.1, Fig. 4). The finer granulation of the neurosecretory material indicates a fast release from the neurosecretory neurons. The diameter of the nuclei was less in caterpillars fed locust-tree leaves (Table 1). Each nucleus of the L1 neurons had one nucleolus (Table 1). It was large and centrally positioned in the nuclei of the L1 cells of the caterpillars from the oak forest.

The number of L1 neurosecretory neurons was smaller in the OL and LO group (Table 1) i.e. in response to novel food. This is also indicated by the significant "population X host plant" interaction in the two-way ANOVA (Table 2).

\section{Activity of the L2 neurosecretory neurons}

The diameter of these neurons was significantly larger in the OO group relative to the other experimental groups (Table 1). The cytoplasm of the L2 neurons of the caterpillars from the oak forest contained a small quantity of the fine-grained $\mathrm{PAF}+$ neurosecretory granules, regardless of diet (Fig.1). A greater quantity of the PAF+ neurosecretory material was observed in the caterpillars from the locust-tree forest population (Fig. 1, Fig. 4). The $\mathrm{PAF}+$ neurosecretory material was medium-grained in the protocerebral L2 neurons of the caterpillars from the LL group, and fine-grained in the LO group (Fig. 1, Fig. 4). The diameters of the nuclei do not differ between experimental groups (Tables 1,2). Two nucleoli were present in all experimental groups except the OO group, where there was only one nucleolus (Table 1, Fig. 4). The nucleoli were large and clearly visible in the OL, LO and LL groups (Fig. 4). Novel food, in both populations (OL and LO groups), was associated with fewer L2 neurosecretory neurons (Table 1). A significant "population x host plant" interaction is recorded for the number of L2 neurosecretory neurons (Table 2), which means that the reaction norms are crossed. 
TABLE 2. A two-way ANOVA of the cytological parameters of 5th instar larvae of Lymantria dispar. The population origin (P) and host plant (H) are fixed factors. The mean squares (MS) were multiplied by 1000 . All abbreviations are explained in Table 1.

\begin{tabular}{|c|c|c|c|c|c|c|c|c|c|}
\hline \multirow{2}{*}{$\begin{array}{l}\text { Source of } \\
\text { variation }\end{array}$} & \multicolumn{3}{|c|}{ DN } & \multicolumn{3}{|c|}{ Dn } & \multicolumn{3}{|c|}{$\mathrm{N}$} \\
\hline & $\mathrm{df}$ & MS & $F$ & $\mathrm{df}$ & MS & $\mathrm{F}$ & $\mathrm{df}$ & MS & $\mathrm{F}$ \\
\hline \multicolumn{10}{|l|}{$\mathrm{L} 1$} \\
\hline $\mathrm{P}$ & 1 & 42.48 & $20.43 * * *$ & 1 & 2.89 & 1.62 & 1 & 0.78 & 0.19 \\
\hline $\mathrm{H}$ & 1 & 14.25 & $6.85^{*}$ & 1 & 11.34 & $6.37^{*}$ & 1 & 0.78 & 0.19 \\
\hline $\mathrm{PxH}$ & 1 & 37.87 & $18.21 * * *$ & 1 & 0.37 & 0.21 & 1 & 52.07 & $12.50^{* *}$ \\
\hline Error & 43 & 2.08 & & 43 & 1.78 & & 8 & 4.17 & \\
\hline \multicolumn{10}{|l|}{$\mathrm{L} 2$} \\
\hline $\mathrm{P}$ & 1 & 0.15 & 0.59 & 1 & 5.16 & 1.16 & 1 & 0.08 & 0.01 \\
\hline $\mathrm{H}$ & 1 & 26.67 & $10.71 * *$ & 1 & 12.18 & 2.74 & 1 & 2.24 & 0.31 \\
\hline $\mathrm{PxH}$ & 1 & 35.00 & $14.06 * * *$ & 1 & 1.77 & 0.40 & 1 & 155.95 & $21.47^{* *}$ \\
\hline Error & 52 & 2.49 & & 52 & 4.44 & & 8 & 7.26 & \\
\hline \multicolumn{10}{|l|}{ L2' } \\
\hline $\mathrm{P}$ & 1 & 35.34 & $67.20 * * *$ & 1 & 1.57 & 0.28 & 1 & 171.58 & $24.63 * *$ \\
\hline $\mathrm{H}$ & 1 & 0.13 & 0.25 & 1 & 0.15 & 0.30 & 1 & 4.44 & 0.64 \\
\hline PxH & 1 & 4.44 & $8.44 * *$ & 1 & 6.42 & 1.13 & 1 & 117.03 & $16.80^{* *}$ \\
\hline Error & 43 & 0.53 & & 43 & 5.67 & & 8 & 6.97 & \\
\hline
\end{tabular}

$* \mathrm{P}<0.05 ; * * \mathrm{P}<0.01 ; * * * \mathrm{P}<0.001$

\section{Activity of the L2' neurosecretory neurons}

The average diameter of the L2' neurosecretory neurons was statistically significantly larger in caterpillars from the locust-tree forest, regardless of the host plant consumed (Tables 1,2).

The L2' neurons in the protocerebri of the caterpillars from the oak forest population had a small quantity of the fine-grained PAF+ neurosecretory product, regardless of food quality (Fig.1, Fig. 4). Large and centrally positioned nucleoli were present in the L2' nuclei. Morphological characteristics of the $\mathrm{PAF}+$ neurosecretory product present in the L2' neurons in the population from the locust-tree forest differed, depending on the diet (Fig. 1, Fig. 4). It was large-grained and present in greater quantities in the LL group than in the LO group, where it was medium-grained (Fig. 1, Fig. 4). The activity of the L2' cells in the population from the locust-tree forest was high because both groups (LL and LO) had two clearly visible and large nucleoli, and their other cytological characteristics were similar.

The number of L2' neurosecretory neurons was significantly greater in the locust-tree forest caterpillars (Table $1,2)$. A decreased number of neurons in response to novel food (Table 1) and a significant "P x H" interaction (Table 2) was recorded for L2' neurosecretory neurons.

\section{Mitotic divisions}

Mitotic divisions were noticeable in the dorsolateral region of the protocerebrum of the 5th instar larvae of Lymantria dispar, that come from the locust-tree forest population (Fig. 3).

\section{Diameter of the corpora allata}

The locust-tree caterpillars had a large CA average diameter, regardless of host plant consumed, whereas in oak forest caterpillars it increased only in response to locust-tree leaves (Table 3).

A highly significant population effect and "population $\mathrm{x}$ host plant" (PxH) interaction were recorded (Table 3 ).

\section{DISCUSSION}

The gypsy moth is a polyphagous folivorous pest, which shows outbreak population dynamics (Barbosa, 1978). The locust-tree is an unfavourable host-plant for the gypsy moth (Perić et al., 1988; Perić-Mataruga, 1997), as its foliage contains larger quantities of allelochemicals (alkaloids and flavonoids) and is of a poorer nutritional quality than oak leaves (Montgomery, pers. comm.). As the gypsy moth population has been present at Bagremara for more than 40 years (Sidor \& Jodal, 1983 ) it is likely to have adapted to a diet of locust-tree leaves. The lack of outbreaks (Sidor \& Jodal, 1983), 


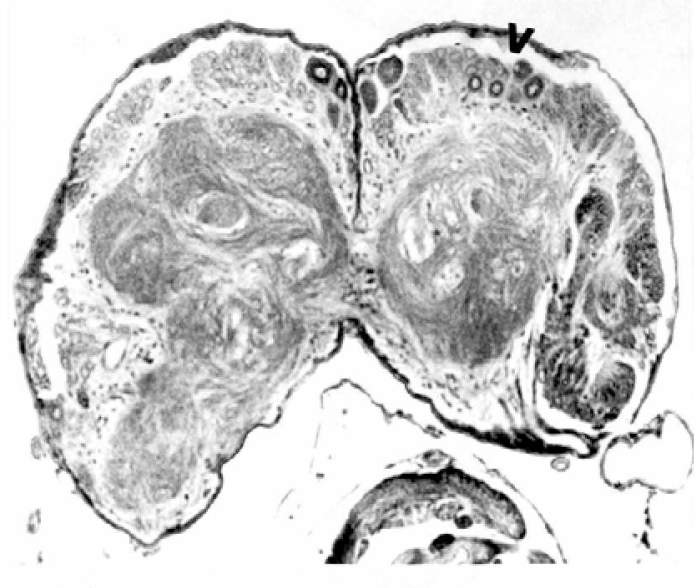

Fig. 2. A frontal cross-section of the brain, at the level of the protocerebrum, of 5 th instar caterpillars of Lymantria dispar. The arrow indicates the position of L1, L2 and L2'dorsolateral neurosecretory neurons (magnification 600x).

delayed hatching (personal observation), prolonged development, modified antioxidative defense (PerićMataruga et al., 1997) and the activity of digestion enzymes in midgut tissue (Lazarević, 2000) have been recorded for gypsy moths from this population. As neurohormones are an inevitable component of the adaptation process this research focused on the neurosecretory neurons (NSN). The results confirm the expected differences in the activity and number of dorsolateral NSN in the two populations (Table 1, 2; Fig. 1; Fig. 4).

The activity of the $\mathrm{L} 1$ neurosecretory neurons was low in the protocerebra of caterpillars from the locust-tree forest population, regardless of the diet (Table 1; Fig. 1; Fig. 4). Feeding for three days on locust-tree leaves also results in an inhibition of the L1 neurosecretory neurons of 5th instar caterpillars of Lymantria dispar (PerićMataruga et al., 1999). Concomitant increase in corpora allata (CA) diameter (Table 3), indicates that L1 NSN

TABLE 3. The means and standard errors for the small and large diameters of the corpora allata (Dca) and mean squares multiplied by 1000 (MS) of a two-way ANOVA for the same trait in the 5th larval instar of Lymantria dispar. The population origin $(\mathrm{P})$ and host plant $(\mathrm{H})$ are fixed factors.

\begin{tabular}{lcccc}
\hline & OO & OL & LO & LL \\
\hline $\begin{array}{l}\text { Dca (mm) } \\
\text { Two-way }\end{array}$ & $52.29 \pm 8.54$ & $68.12 \pm 2.13$ & $70.12 \pm 2.01$ & $67.50 \pm 3.31$ \\
ANOVA & df & MS & F \\
P & 1 & 17.4 & $5.50^{*}$ & \\
H & 1 & 9.3 & 0.51 & \\
PxH & 1 & 18.0 & $5.7^{*}$ \\
Error & 11 & 3.2 & & \\
\hline
\end{tabular}

* $\mathrm{P}<0.05$

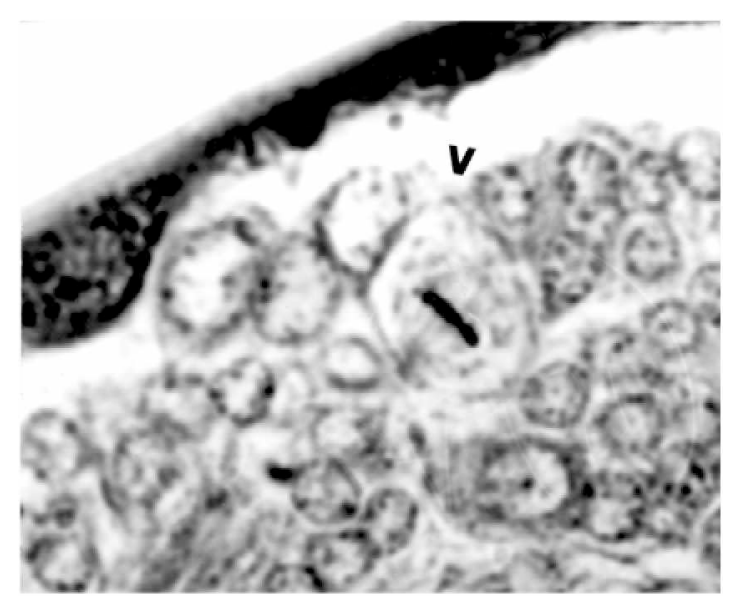

Fig. 3. Mitotic divisions in the dorsolateral region of the protocerebrum of 5 th instar Lymantria dispar from the locust-tree population (magnification 1100x).

possibly synthesize allatostatins. This was proved in other insects by immunocytochemical methods (Veelaert et al., 1995) and such studies should be done on the gypsy moth. An increase in CA activity and in the titer of juvenile hormones when stressed is common in insects (Chernysh, 1991; Hirashima et al., 1995; Gruntenko et al., 2000). For example, it results in an increase in consumption of nutritionally poor food (Felton, 1996), changes in the activities of the digestive enzymes (Ivanović \& Janković-Hladni, 1991) and induction of detoxifying enzymes (Terriere \& Yu, 1973). Thus it is now important to demonstrate what neurosecretions are produced by L1 NSN, and the rates of JH synthesis and/or the titers of $\mathrm{JH}$ in the haemolymph.

A three-day change in the quality of the diet fed to 5th instar gypsy moth caterpillars results in an increase in both the synthesis and secretory activity of the L2 neurosecretory neurons (Perić-Mataruga et al., 1999). The response of L2 neurosecretory neurons to the quality of food depended on the population's origin, i.e. their trophic adaptation. The unfavourable diet (locust-tree leaves) resulted in an activation of the L2 neurons in the population from the oak forest, whereas the activity of these neurons was high in locust-tree caterpillars, regardless of the diet (Table 1; Fig. 1; Fig. 4). It is probable that differences in the activity and number of dorsolateral neurosecretory neurons, when subjected to nutritive stress, modulate the metabolic response of gypsy moth caterpillars.

Neither short-term (Perić-Mataruga et al. 1999) nor long-term trophic stress changed the activity of the L2' NSN, although the number of these neurons increased in locust-tree caterpillars (Table 1; Fig. 1; Fig. 4). It is probable that these cells synthesize neurohormones involved in morphogenesis. By using monoclonal antibodies, it was shown that the large neurosecretory neurons of the dorsolateral region of the lepidopteran brain synthesize 


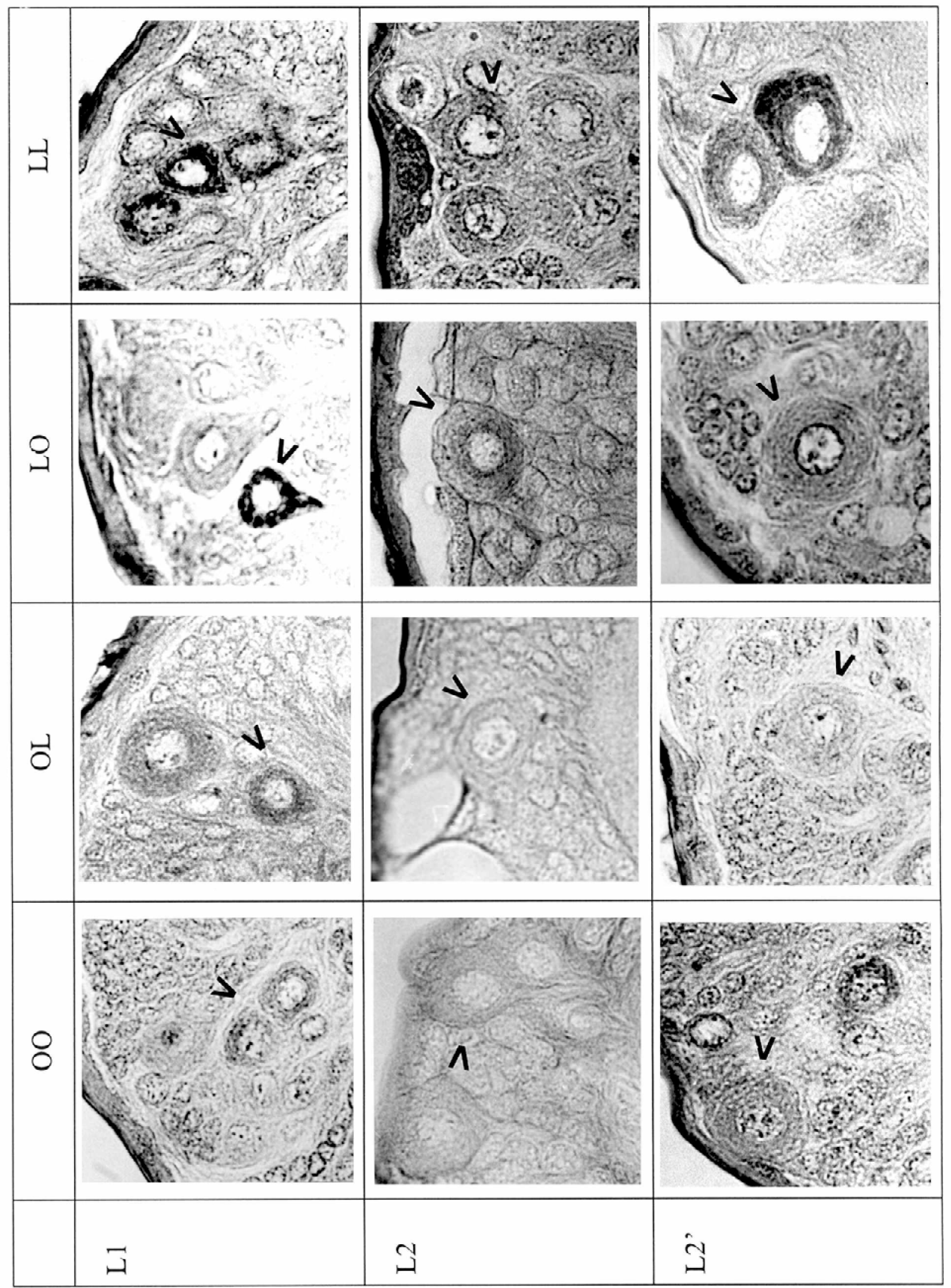

Fig. 4. Protocerebral L1, L2 and L2' neurosecretory neurons of 5th instar caterpillars of Lymantria dispar from two populations fed on different host plants $(1000 \mathrm{x})$. The arrows indicate the position of L1, L2 and L2'dorsolateral neurosecretory neurons. The abbreviations are as in Table 1. 
the large form of the prothoracicotropic neurohormone (PTTH) (Kawakami et al., 1990; Gray et al., 1994), which stimulates synthesis and release of ecdysone. In addition to its morphogenetic function ecdysone is also involved in overcoming the negative effects of nutritive stress such as the effect of flavonoids (Chernysh 1991; Yu, 1995). If this true in the gypsy moth, then the increased number of L2' NSN in locust-tree caterpillars could be adaptive and results in a higher haemolymph ecdysone titer in response to the flavonoids in locust-tree leaves.

The central nervous system and neurohormones regulate a large number of insect traits and are an inevitable component of the process of adaptation to a changing environment (Ivanović \& Janković-Hladni, 1991). Characteristics of the response as well as the ability to respond to a changing environment are controlled by two independent systems: the central nervous system (neuroendocrine factors) and target cells (receptor system). A "regulatory dialogue" between them leads to better matching with the environmental changes, i.e. adaptive plasticity (Nijhout, 1999).

The increase in number of dorsolateral neurons in response to the nutritive stress provoked by a diet of locust-tree leaves is characteristic of locust-tree caterpillars (Tables 1, 2). Similar results were obtained using 2nd, 4th and 6th instar caterpillars (Perić, 1990) as well as 5th instar caterpillars using different histological techniques (Perić-Mataruga, 1997). The adaptive value of such a response may be in the reprogramming of the development to enable a more efficient processing of nutritionally inadequate food.

ACKNOWLEDGEMENTS. This work was supported by the Ministry for Science and Technology of Serbia, grant \#03E13.

\section{REFERENCE}

Agui N., Granger N.A., Bollenbacher W.E. \& Grlbert L.I. 1979: Cellular localization of the insect prothoracicotropic hormone: In vitro assay of a single neurosecretory cell. Proc. Natl. Acad. Sci. USA 76: 5694-5698.

Barbosa P. 1978: Host plant exploatation by the gypsy moth, Lymantria dispar. Entomol. Exp. Appl. 24: 28-37.

Bogus M.I. \& SCHELLER K. 1994: Identification of allatotropinsecreting cells in the brain of an insect larva. Naturwissenschaften 81: 87-89.

Borkovec A.B. \& Gelman D.B. (eds) 1986: Insect Neurochemistry and Neurophysiology. Humana Press, Clifton, NJ, 523 pp.

ChernYsh S.I. 1991: Neuroendocrine system in insect stress. In Ivanović J. \& Janković-Hladni M. (eds): Hormones and Metabolism in Insect Stress. CRC Press, Boca Raton, pp. 69-97.

Dai J.D., Mizoguchi A., Satake L., Ishizaki H. \& Gilbert L.I. 1994: Developmental changes in the PTTH content of the Bombyx mori brain-retrocerebral complex and hemolymph: Analysis by immunogold electron microscopy qualitative image analysis and tissue resolved fluoroimmunoassay. Dev. Biol. 171: 212-223.

DOWNER R.G.H. \& LAUFER H. 1984: Endocrinology of Insects. Alan R. Liss, Inc., New York, 707 pp.
Elkinton J.S. \& LiebHold A.M. 1990: Population dynamics of gypsy moth in North America. Annu. Rev. Entomol. 35: 571-596.

EWEN A.B. 1962: An improved aldehyde fuchsin staining technique for neurosecretory products in insects. Trans. Am. Micr. Soc. 81: 94-96.

Felton G.W. 1996: Nutritive quality of plant protein; Source of variation and insect herbivore responses. Arch. Insect Biochem. Physiol. 32: 107-130.

Fescemyer H.W., Masler E.P., Kelly T.J. \& Lusby W.R. 1995: Influence of development and prothoracicotropic hormone on the ecdysteroids produced in vitro by prothoracic glands of female gypsy moth (Lymantria dispar) pupae and pharate adults. J. Insect Physiol. 41: 489-500.

GilbeRT L. I., RybCYNSKI R. \& Tobe S.S. 1996: Endocrine cascade in insect metamorphosis. In Gilbert L.I., Tata J.R. \& Atkinson B.G. (eds.): Metamorphosis: Postembryonic Reprogramming of Gene Expression in Amphibian and Insect Cells. Academic Press, New York, pp. 60-98.

Gray R.S., Muehleisen D.P. \& Bollenbacher W.E. 1994: Multiple peptide expression by the L-NSC in the tobacco hornworm, Manduca sexta. In Borkovec A.B. \& Loeb M.J. (eds): Insect Neurochemistry and Neurophysiology 1993. CRC, Boca Raton, FL pp. 251-254.

Gruntenko N.E., Khlebodarova T.M., Vasenkova I.A., Surhanova M.JH., Wilson T.G. \& Rauschenbach I.Yu. 2000: Stress-reactivity of a Drosophila melanogaster strain with impaired juvenile hormone action. J. Insect Physiol. 46: 451-456.

HigHNAM K.C. 1967: Insect endocrinology. J. Endocrinology 37: $6-8$.

Hirashima A., Takeya R., Taniguchi E. \& Eto M. 1995: Metamorphosis, activity of juvenile-hormone esterase and alteration of ecdysteroid titres: Effects of larval density and various stress on the red flour beetle, Tribolium freemani Hinton (Coleoptera: Tenebrionidae). J. Insect Physiol. 41: 383-388.

Hiruma K. \& AGUI N. 1977: Relationship between histological changes and functions of the neurosecretory cells in the brain of the cobbage armyworm, Mamestra brassicae L. Appl. Entomol. Zool. 12: 42-49.

ILLYINSKAYA N.B. 1968: The dynamics of seasonal change resistance of insects in relation to diapause and neurosecretion. Acta Soc. Zool. Bohemoslov. 32: 217-222.

Ivanović J., Janković-Hladni M., Stanić V., Nenadović V. \& FRUŠść M. 1989: The role of neurosecretion and metabolism in development of an oligophagous feeding habit in Morimus funereus larvae (Col.: Cerambycidae). Comp. Biochem. Physiol. 94A: 167-171.

IVANOVIĆ J. \& JanKović-HLADNI M. 1991: Hormones and Metabolism in Insect Stress. CRC Press, Boca Raton, pp.178.

Ivanović J.P., Stanić V., Raushenbach I. YU., Janković-HLadnI M., Nenadović V. \& BudKer V.G. 1991: Influence of nutrition substrate on neuroendocrine system in the ontogenesis of a cerambycid Morimus funereus (Insecta). Zh. Obshch. Biol. 52: 205-213.

Kawakami A., Kataoka H., OKa T., Mizoguchy A., KimuraKawakami M., Adachi T., Iwami M., Nagasawa H., Suzuri A. \& IshIZAKI H. 1990: Molecular cloning of the Bombyx mori prothoracicotropic hormone. Science 247: 1333-1335.

Kelly T.J., Masler E.P., Thyagaraja B.S., Bell R.A. \& BorKovec A.B.1986: Prothoracicotropic hormone stimulation of ecdysone synthesis by the prothoracic glands of the gypsy moth, Lymantria dispar. In Borkovec A.B. \& Gelman D.B. (eds): Insect Neurochemistry and Neurophysiology. Humana Press, Clifton, NJ, pp. 327-330. 
KIND T.V. 1968: Functional morphology of the neurosecretory system during certain types of larval diapause. Proc. $13^{\text {th }}$ Int. Congr. Entomol., Moscow, pp. 396-397.

LAZAREvić J. 2000: Physiological and Genetic Mechanisms of Adaptation to Unsuitable Nutrition in Lymantria dispar $L$. $\mathrm{PhD}$ thesis, Fac. Nat. Math. Sci., University of Belgrade, Belgrade, $356 \mathrm{pp}$.

Liebhold A.M., Gottschalk K.W., Muzika R.M., Montgomery M.E., Young R., O’DAY K. \& Kelley B. 1995: Suitability of North American tree species to the gypsy moth: A summary of field and laboratory tests. USDA For. Serv. Gen. Techn. Rep. NE-211.

Loeb M.J. \& Hayes D.K. 1980: Neurosecretion during diapause development in brains of mature embryos of the gypsy moth, Lymantria dispar. Ann. Entomol. Soc. Am. 73: 432-436.

Meng-Ping T., Rong K., Zong-Shun W., John G.S.J. \& ChiHMrNG Y. 2001: Immunolocalization and possible effect of a moth allatotropin-like substance in a fly, Phormia regina (Diptera: Calliphoridae). J. Insect Physiol. 47: 233-244.

MitsunAshi J. 1963: Histological studies on the neurosecretory cells of the brain and on the corpus allatum during diapause in some lepidopterous insects. Tokyo Bull. Nat. Inst. Agric. Sci. Ser. C. 16: 67-118.

Ninнout H.F. 1999: Control mechanisms of polyphenic development in insects. Bio Sci. 49: 181-192.

OKUDA T. \& TANAKA S. 1997: An allatostatic factor and juvenile hormone synthesis by corpora allata in Locusta migratoria. $J$. Insect Physiol. 43: 635-641.

PERIĆ V. 1990: The effect of feeding substrates on the development and activity of the protocerebral neurosecretory neurons Lymantria dispar caterpillars from different populations. M.Sci Thesis, University of Belgrade, Biological faculty, 98 pp.

Perić V., Janković-Hladni M. \& Ivanović J. 1988: The effect of different feeding substrates on the development of Lymantria dispar L. Plant Prot. 39: 133-138.

Perić-Mataruga V. 1997: The Activities of the Antioxidative System Enzymes and of Protocerebrum Neurosecretory Cells under Nutritional Stress Conditions in Lymantria Dispar L. Caterpillars of Different Population Origin. PhD Thesis, Fac. Nat. Math. Sci., University of Belgrade, Belgrade, 219 pp.

Perić-Mataruga V., Blagojević D., Spasić M.B., Ivanović J. \& JANKović-HLADNI M. 1997: Effect of the host plant on the antioxidative defence in the midgut of Lymantria dispar $\mathbf{L}$. caterpillars of different population origins. J. Insect Physiol. 43: 101-106.
Perić-Mataruga V., Lazarević J. \& Nenadović V. 1998: The effects of a short-term unsuitable diet on protocerebrum neurosecretory neurons of Lymantria dispar L. caterpillars originating from two populations. In Adamovic Ž (ed.): The Gypsy Moth Outbreaks in Serbia, BIG, Beograd, pp. 95-129.

Perić-Mataruga V., Lazarević J. \& Nenadović V. 1999: Short term effects of host plant shift on lateral protocerebrum neurosecretory neurons in Lymantria dispar L. caterpillars. Pesticides 14: 281-298.

Pszczolkowski M.A. \& Chiang A.S. 2000: Effects of chilling stress on allatal growth and juvenile hormone synthesis in the cockroach, Diploptera punctata. J. Insect Physiol. 46: 923-931.

RaABE M. 1982: Insect Neurohormones. Plenum Press, New York and London, $352 \mathrm{pp}$.

Rossiter M.C. 1991: Maternal effects generate variation in life history: consequences of egg weight plasticity in the gypsy moth. Funct. Ecol. 5: 386-393.

ScharRer B. \& Weitzman M. 1970: Current problems in invertebrate neurosecretion. In Bargmann W. \& Scharrer B. (eds): Aspects of Neuroendocrinology. Springer-Verlag, Berlin, Heidelberg, New York, pp.1-23.

Sidor C. \& JodAl I. 1983: The gypsy moth Porthetria dispar L. health investigation results in the locust tree forest "Bagremara" near Bačka Palanka. Plant Prot. 34: 445-455.

SoKal R.R. \& RohlF F.J. 1981: Biometry. Freeman, San Francisco, $859 \mathrm{pp}$.

STOCKHOFF B.A. 1991: Starvation resistance of gypsy moth Lymantria dispar (L.) (Lepidoptera: Lymantriidae): Tradeoffs among growth, body size, and survival. Oecologia 88: $422-429$.

TERRIERE L.C. \& Yu S.J. 1973: Insect juvenile hormones: induction of detoxifying enzymes in the housefly and detoxication by housefly enzymes. Pestic. Biochem. Physiol. 3: 73-83.

THOMSEN M. 1965: The neurosecretory system of the adult Calliphora erythrocephala. II. Histology of the neurosecretory cells of the brain and some related structures. Z. Zellforsch. 67: 693-717.

Veelaert D., Tobe S.S., Yu G.G., Schoofs L. \& Loof A.D. 1995: Allatostatic and allatotropic factors in the brain of the desert locust Schistocerca gregaria. Belg. J. Zool. 125: 243-249.

Yu S.J. 1995: Allelochemical stimulation of ecdysone 20monooxygenase in fall armyworm larvae. Arch. Insect Biochem. Physiol. 28: 365-375.

Received February 5, 2001; revised May 22, 2001; accepted June 19, 2001 